\title{
Development of Warning Device in Risk Situations for Children with Hearing Impairment at Low Cost
}

\author{
Kevin Rodriguez-Villarreal ${ }^{1}$, Zumaeta-Mori Jhon ${ }^{2}$, Alva Mantari Alicia ${ }^{3}$, Roman-Gonzalez Avid ${ }^{4}$ \\ Image Processing Research Laboratory (INTI-Lab) \\ Universidad de Ciencias y Humanidades \\ Lima, Perú
}

\begin{abstract}
Hearing impairment is the partial or total loss of hearing. There are approximately 34 million hearing impaired children in the world. The equipment used as a means of communication to improve interaction with society is very expensive, so in this study was built an electronic device with the ability to recognize some words configured as an emergency message. This equipment will be used as a basic means of communication for hearing impaired children at a very low price. The equipment consists of a transmitter and a receiver, which communicate over Wi-Fi 802.11 at distances between $0 \mathrm{~m}$ and $95 \mathrm{~m}$ using low-power electronic devices and recent technology such as WeMos D1 mini Lite cards. This device was tested on approximately 20 people caring for hearing impaired children, obtaining a measure of approval of approximately $74 \%$. This is the first step in research that we plan to continue to reduce health gaps and improve communication for children with disabilities. Our group works for preventive health, reducing health gaps in the most vulnerable population.
\end{abstract}

Keywords-Hearing disability; device; low cost; algorithm; communication

\section{INTRODUCTION}

In the world, there are approximately 466 million people with a hearing-impairment (in adults over $40 \mathrm{~dB}$ and in children at $30 \mathrm{~dB}$ ) of which 34 million children, according to the World Health Organization [1]. Hearing impairment in children is that difficulty or inability to listen, due to partial or total loss of hearing ability, which can occur in one or both ears. Some of the causes of hearing impairment in children can be trauma, otitis, meningitis, excessive exposure to noise or strong medications that could cause some impact on the auditory nerve [2]. Hearing impairment in children is the third most frequent disability in Peru [3], and the index increases more and more, because a diagnosis is not made at an early age, so this condition can be aggravated in all infants who they present it [4]. In Peru 1 to 6 Peruvians are born every day with severe to profound hearing loss, there are no centers with a good infrastructure to help them. Despite the efforts made by the National Program for Early Management of Hearing Loss, it is not enough to care for all children [5]. Hearing-impairment in children in Peru has only been diagnosed in 30\%. Hearingimpairment in children represents a severe public health problem, which the State should have as a priority, since progress can be dangerous throughout the country, despite having the hearing loss program that has granted about 500 implants cochlear, much more is needed to provide optimal care to all children who require it. This situation has been caused by the lack of medical instrumentation, which allows this condition to be diagnosed, in addition to lacking an institution with the necessary spaces and conditions to perform patient surgeries. It is estimated that only $30 \%$ of children with sensory hearing loss on both sides have been diagnosed and received a surgical intervention with a cochlear implant, through the aforementioned program [6]. About 300 children with hearing disabilities are born each year, of which only about 90 patients would be benefiting, while another 210 are not receiving treatment or diagnosis [7]. The solution for some of them is the cochlear implant, also known as the bionic ear, is that device that is implanted through surgery, helping to improve hearing- impairment in children, helping them overcome these problems originating in the inner ear or cochlea. This procedure is recommended for those children who have sensorineural hearing loss, allowing them to recover their hearing by $85 \%$, preventing the problem from getting worse and becoming deaf, but this is a very expensive procedure. After undergoing this operation, children should receive language therapies to complete their communication process and be able to acquire learning in an optimal way, since hearing-impairment often causes difficulties in the acquisition of reading skills, because Communication is run over by this condition. This research seeks to provide an alternative communication and alert for children in a state of emergency through a device for non-visual communication. That is, the child can interpret the vibrations or visual stimuli activated by words of the person in charge of his care. The equipment works in such a way that it converts the message sent by the tutor into vibrations produced by the motors or into light emitted by the LEDs.

Translated with www.DeepL.com/Translator (free version).

\section{POPULATION AND SAMPLE}

\section{A. Sample}

For the development of the communication device, one of the most important steps was the choice of the most relevant keywords. Through a survey was built in which 44 people over the age of 18 participated, who chose 7 words from a group of 19 words taken from emergency manuals for children in general. The result of this survey can be seen in Table I, where you can see that the selected words are:

- $\operatorname{Help}(56.8 \%)$

- Stay with me (52.3\%) 
- Stay calm $(52.3 \%)$

- Emergency $(43.2 \%)$

- Stop $(43.2 \%)$

- Watch out $(40.9 \%)$

- $\operatorname{SOS}(36.4 \%)$

TABLE. I. TABLE OF PHRASES USED IN EMERGENCY SITUATIONS

\begin{tabular}{|l|l|l|l|}
\hline Consulted Phrases & Frequency & $\begin{array}{l}\text { Relative } \\
\text { Percentage }\end{array}$ & $\begin{array}{l}\text { Absolute } \\
\text { Percentage }\end{array}$ \\
\hline Consulted Phrases & 16.00 & 36.4 & 5.63 \\
\hline SOS & 19.00 & 43.2 & 6.69 \\
\hline Emergency & 14.00 & 31.8 & 4.93 \\
\hline Urgent & 19.00 & 43.2 & 6.69 \\
\hline Stop & 12.00 & 27.3 & 4.23 \\
\hline Run & 25.00 & 56.8 & 8.80 \\
\hline Help & 13.00 & 29.5 & 4.58 \\
\hline Attentive & 14.00 & 31.8 & 4.93 \\
\hline Help me & 12.00 & 27.3 & 4.23 \\
\hline Do you feel any pain? & 9.00 & 20.5 & 3.17 \\
\hline I love you & 23.00 & 52.3 & 8.10 \\
\hline Stay with me & 18.00 & 40.9 & 6.34 \\
\hline Watch out & 13.00 & 29.5 & 4.58 \\
\hline Look at me & 13.00 & 29.5 & 4.58 \\
\hline protect yourself & 3.00 & 6.8 & 1.06 \\
\hline get moving & 12.00 & 27.3 & 4.23 \\
\hline Where are you? & 15.00 & 34.1 & 5.28 \\
\hline Do you feel any discomfort? & 11.00 & 25.0 & 3.87 \\
\hline Slowly & 23.00 & 52.3 & 8.10 \\
\hline Stay calm & & & \\
\hline & & & \\
\hline
\end{tabular}

\section{Methodology}

The work is based on the design of two electronic devices, capable of communicating with each other over distances greater than $80 \mathrm{~m}$ using Wi-Fi transmission. Applying lowpower devices that are wireless microcontrollers with $\mathrm{Wi}-\mathrm{Fi}$ communication, specifically 802.11. In this sense, the application of the device consists of sending voice commands through a microphone connected to a voice recognition module, which recognizes the pre-recorded words and send them via the WeMos D1 mini Pro transmitter device to the receiver (Fig. 1). This receiver converts the data sent by the transmitter into sensitive stimuli that are manifested through dc motors and RGB LEDs.

\section{A. Description of the main Components}

1) Wemos DI mini Lite: This low-power and highly functional device is a new technology, so there is not much information about it. This card is controlled by an ESP8266 and a Wi-Fi chip, which allows it to transmit over distances greater than $80 \mathrm{~m}$ (Fig. 2).

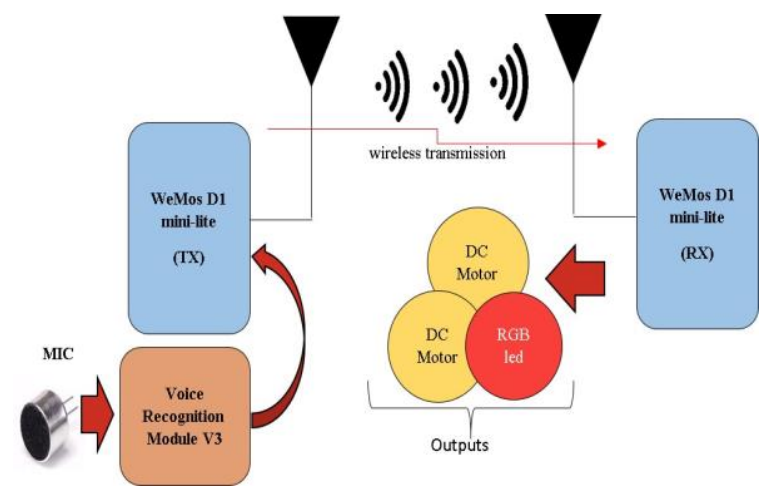

Fig. 1. Circuit Block Diagram.
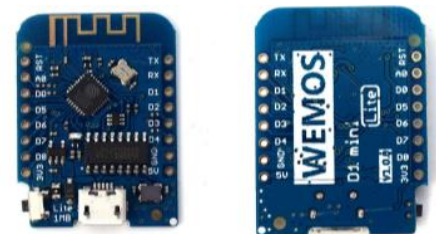

Fig. 2. WeMos D1 mini Lite Development Board.

There are variants of the ESP8286 with more functionalities and other aggregates in the hardware, either with greater number of pins, greater memory capacity and greater range in your Wi-Fi antenna [8] (Details Table II).

2) Voice recognition module v3: The voice recognition module used for the recording of the words that will cause an action on the receiving device, communicates through the serial port Tx and Rx, in order to record the words to be used, in addition to this the module only recognizes the voice of the person who recorded it according to the frequency of his voice, thus preventing outsiders from manipulating him. The parameters that this module handles are those shown in Table III (Fig. 3). For the recording of the words, 5 of a list that was distributed as a survey were initially used. The module only picks up 7 voice commands at the same time, and if you want to record more they must be loaded in groups of 7 , it supports a maximum of 80 commands in total with a duration of $1500 \mathrm{~ms}$. However, if almost $100 \%$ operation is required, the environmental conditions must be ideal, that is, without noise in the environment.

3) Micro vibrator CEBEK C-6070: The purpose of using vibrators and non-motors, is due to the application that this device has, for people with low hearing sensitivity the vibrating of the vibrator next to the ear is more perceived than a movement of a conventional DC motor, the details are those shown in Table IV. The size of the micro vibrator allowed it to be placed on both sides of the headset and thus activated with the voltage of the WeMos D1 mini Lite [9] (Fig. 4).

\section{B. Operation of the Complete System}

The development of the prototype and its understanding are detailed in the following flowchart, in which the following logic is observed, from the creation part of the algorithm to its implementation. 
TABLE. II. CHARACTERISTICS OF THE WEMOS D1 MINI ESP8285

\begin{tabular}{|l|l|}
\hline Parameter & Value \\
\hline Input Voltage & $3.3 \mathrm{v}$ \\
\hline Flash memory & $1 \mathrm{MB}$ \\
\hline Communication Support & I2C \\
\hline Digital Inputs & 11 \\
\hline Wi-Fi Protocol & $802.11 \mathrm{~b} / \mathrm{g} / \mathrm{n} / \mathrm{e} / \mathrm{i}$ \\
\hline Operating band & ISM $2.4 \mathrm{GHz}$. \\
\hline Input Port & Micro USB \\
\hline Analog Pin & A0 (1) \\
\hline SPI Pins & D5,D6,D7,D8 (4) \\
\hline Current & 500 mAh \\
\hline Compatibility & Arduino \\
\hline
\end{tabular}

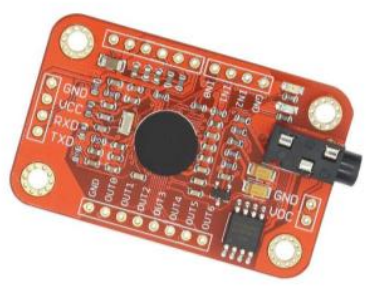

Fig. 3. Voice Recognition Module v3.

TABLE. III. CHARACTERISTICS OF THE Voice RECOGNITION MOdULE v3

\begin{tabular}{|l|l|}
\hline Parameter & Value \\
\hline Input Voltage & $4.5-5.5 \mathrm{~V}$ \\
\hline Current & $<40 \mathrm{~mA}$ \\
\hline Digital Interface & $5 \mathrm{~V}$ TTL level for UART interface and GPIO \\
\hline Analog Interface & $3.5 \mathrm{~mm}$ mono-channel microphone connector \\
\hline Recognition accuracy & $99 \%$ (under ideal environment) \\
\hline
\end{tabular}

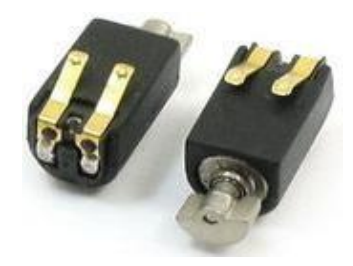

Fig. 4. Micro Vibrator Cebek C-6070.

TABLE. IV. CHARACTERISTICS OF THE CEBEK C-6070 Micro ViBRATOR

\begin{tabular}{|l|l|}
\hline Parameter & Value \\
\hline Input Voltage & $1.3 \mathrm{v}$ \\
\hline Average speed & $8000 \mathrm{rpm}$ \\
\hline Average current & $75 \mathrm{~mA}$ \\
\hline Resistance & $11,7 \mathrm{~W} \pm 10 \%$ \\
\hline Approximate weight & $1.8 \mathrm{~g}$ \\
\hline
\end{tabular}

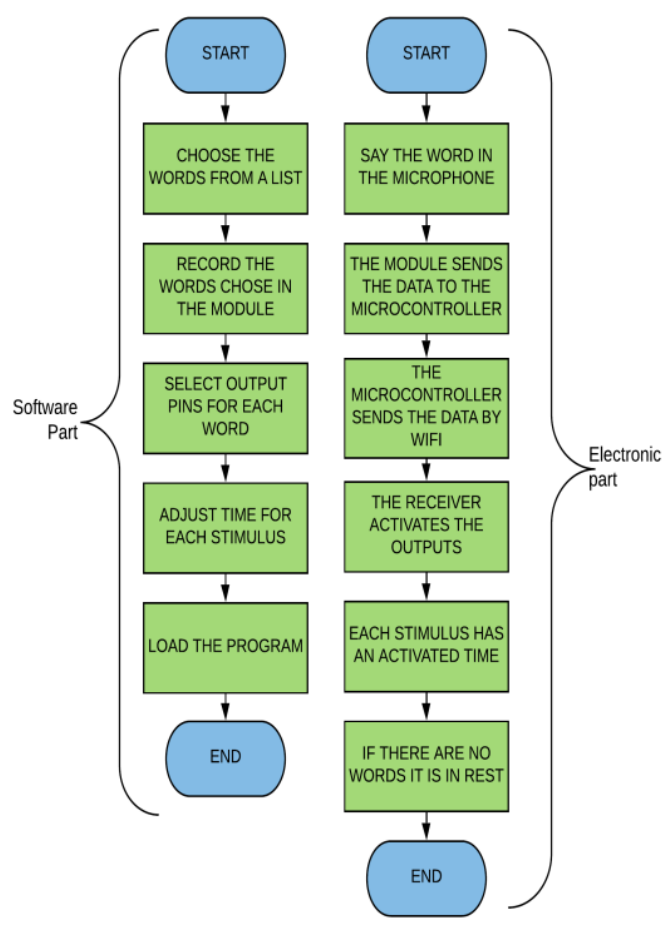

Fig. 5. Circuit Flow Diagram.

In the flowchart of Fig. 5. It is observed, the software part with the steps for the configuration of the voice recognition module through the Arduino IDE, and also the procedure of the hardware part, such as sending the message and What happens once this message is picked up by the receiver activating the different sensory devices attached to the headphones.

\section{Limitations}

The development of the device could be improved by including more words in the algorithm, currently we only have 7 words for identification. In addition to having been tested for usability and acceptability by the target population (parents, teachers and hearing-impaired children). At the same time, see how to improve performance and set a minimum acceptable age in the population for the application of the device.

\section{RESULTS}

The development of this prototype is intended to provide an alternative to problems of hearing impairment, through applied electronics. We verify the operation of the devices created, both the transmitter and the receiver. For this, it was decided to adapt the transmitter circuit in a perforated Bakelite, along with some straps to use on the wrist as a bracelet (Fig. 6).

However, the design of the receiver was adapted to wireless headphones, since the purpose of this is to be able to provide freedom in the user's hands so that it moves with total comfort, also having it in a part that is not uncomfortable for the person who will use it. 


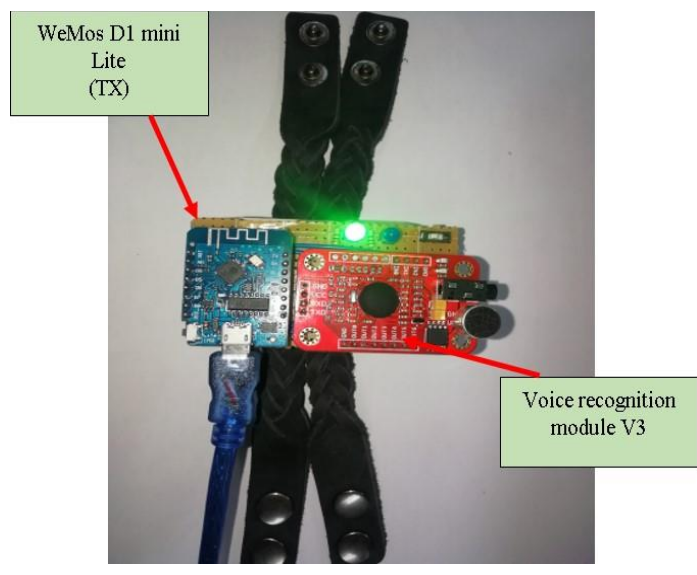

Fig. 6. Transmitter Bracelet.

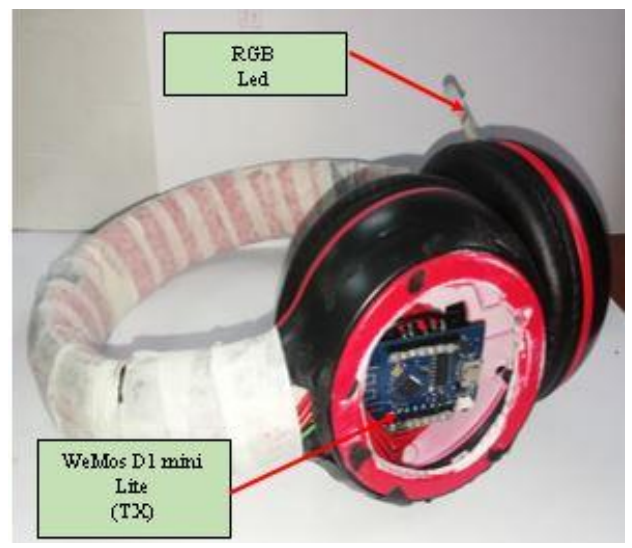

Fig. 7. Receiver Headphones.

As seen in Fig. 7, on one side of the headphones, an RGB LED was placed, which turns red, green or blue, depending on the word sent by the transmitter bracelet. The word already pre-recorded can activate a visual stimulus for a while and then turn it off or you can activate it indefinitely until the same message sent is said again. On the other hand, on both sides of the headset, there is an unbalanced DC motor on its axis, which has the function of improving its vibration, so that the stimulus feels more efficiently through the earpiece protectors.

The prototype was tested and has a range from 0 meters to 95 meters from the transmitter (bracelet used by the caregiver) with the receiver (headphones used by the child).

A small pilot was carried out in 20 carers of hearingimpaired children, obtaining a satisfaction of 7.4 out of a maximum of 10 points, it is worth mentioning that the participants did not have another device with these characteristics and their primary means of communication was sign language.

\section{CONCLUSIONS}

A low-cost device for alternate communication between hearing impaired people was developed at low cost (approx. $\$ 85$ ). Within the device was included a word identification algorithm that allowed a communication addressed to people of scarce resources. The adaptation of the device for the initial pilot is based on the training of the child and the tutor. For this reason, a child with a minimum age of 9 years is needed. The reception of such a device in the families was positive due to the consequences of its use in the inclusion of the child in the community.

The development of this prototype is intended to be an alternative and is the first phase of an investigation that includes the construction of the equipment, its use and implementation in families with hearing impaired children. There is no such equipment on the market [9]. We offer the possibility of non-visual communication to these children. This work allows to open a whole branch of research related to the inclusion and the improvement of the quality of life in an economic way.

\section{FUTURE WORK}

A next step in this study corresponds to the improvement of the equipment, to improve the distance of transmission of the message and at the same time to be able to store more quantity of words that allow to have a better communication. and that is not so limited. The inclusion of more people with moderate to severe hearing impairment and who do not have other options to improve communication at a low cost due to the inaccessibility of instruments for this purpose.

\section{ACKNOWLEDGMENT}

We want to thank the Universidad de Ciencias y Humanidades for the support in carrying out this study. We continue to work for preventive health, and to reduce health gaps throughout our country.

\section{REFERENCES}

[1] K. R. White, I. Forsman, J. Eichwald, and K. Munoz, "The evolution of early hearing detection and intervention programs in the United States," Semin. Perinatol., vol. 34, no. 2, pp. 170-179, Apr. 2010.

[2] P. M. Watkin, M. Baldwin, and G. McEnery, "Neonatal at risk screening and the identification of deafness.," Arch. Dis. Child., vol. 66, no. 10 Spec No, pp. 1130-1135, Oct. 1991.

[3] "PERÚ - INEI: Perú: Resultados Definitivos de los Censos Nacionales 2017." [Online]. Available: https://www.inei.gob.pe/media/Menu Recursivo/publicacionesdigitales/Est/Lib1544/. [Accessed: 06-Aug2019].

[4] A. Erenberg, J. Lemons, C. Sia, D. Trunkel, and P. Ziring, "Newborn and infant hearing loss: detection and intervention.American Academy of Pediatrics. Task Force on Newborn and Infant Hearing, 1998- 1999," Pediatrics, vol. 103, no. 2, pp. 527-530, Feb. 1999.

[5] J. Rado-Triveño and J. Alen-Ayca, "Evaluación de las otoemisiones acústicas en relación a los potenciales evocados auditivos de tronco cerebral en niños," Rev. Peru. Med. Exp. Salud Pública, vol. 33, pp. 706712, Dec. 2016.

[6] O. Hernández Fernández, L. Zamora Rodríguez, and V. Abreu García, "El implante coclear: una opción para el niño cubano con discapacidad auditiva," Medicentro Electrónica, vol. 19, no. 3, pp. 167-170, Sep. 2015.

[7] C. Cáceres and S. Rosario, "Estudio epidemiológico del implante coclear en el Perú de 1999 al 2009," Pontif. Univ. Católica Perú, Sep. 2018.

[8] A. K. Evans and K. Kazahaya, "Canal atresia: "surgery or implantable hearing devices? The expert's question is revisited," Int. J. Pediatr. Otorhinolaryngol., vol. 71, no. 3, pp. 367-374, Mar. 2007.

[9] "American National Standard Methods of Measurement of Compatibility between Wireless Communications Devices and Hearing Aids," C63192011Revision ANSI C6319-2007 - Redline, pp. 1-184, May 2011. 